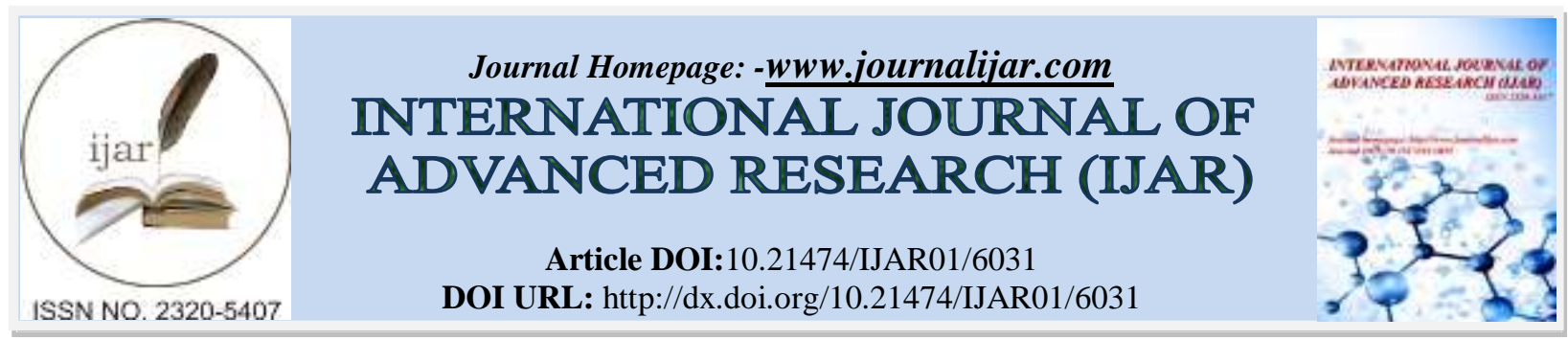

RESEARCH ARTICLE

\title{
THE PREVALENCE OF AVASCULAR NECROSIS IN ADULTS WITH SICKLE CELL DISEASE IN KING FAHAD HOSPITAL.
}

Sarah A. Elmaghraby ${ }^{1}$, Saud H. Balelah ${ }^{2}$, Hibah A. Almahdi ${ }^{1}$, Hatem M. Habib ${ }^{3}$, Duha D. Al-loqmani ${ }^{1}$, Reem J. Tharwat ${ }^{1}$, Nada H. Mahmoud ${ }^{1}$, Fatma S. Baik ${ }^{1}$ andFatema K. Al-Madani ${ }^{1}$.

1. Medical Intern, Taibah university.

2. Consultant Hematologist.

3. OB/GYN Resident, MMCH.

\section{Manuscript Info}

\section{Manuscript History}

Received: 11 October 2017

Final Accepted: 13 November 2017

Published: December 2017

Key words:-

Sickle, Avascular, Necrosis, Prevalence.

\section{Abstract}

Introduction: Sickle cell disease is the commonest genetic blood disorder. Every year, around 330,000 babies are born with inherited hemoglobin disorder, $83 \%$ of them have Sickle cell disease. Avascular necrosis is a serious complication threatening the quality of patients' lives.

Objective: To study the prevalence of avascular necrosis in adult patients with sickle cell disease at King Fahad Hospital.

Methods: A retrospective study carried on (220) sickle cell disease patients mainly from Madinah region in Saudi Arabia from 2010 to 2017.The data were collected from medical records and use of questionnaire format .

Results: According to the results of this study most patients were males, aged between 26 and 40 years. Of 220 sickle cell anemia patients attended at King Fahad Hospital in a period of 7 years, (7.3\%) had avascular necrosis. The majority of patients have a lower hemoglobin and hematocrit levels $(7.0-10.4 \mathrm{~g} / \mathrm{dl}$ and less than $40 \%$, respectively). About $57.9 \%$ of patients take hydroxyurea. $86.1 \%$ have normal serum calcium levels .

Conclusion: This study aimed to assess the prevalence of avascular necrosis in adult patients with sickle cell anemia at King Fahad Hospital. Of 220 sickle cell anemia patients attended at King Fahad Hospital in a period of 7 years, $16(7.3 \%)$ had avascular necrosis. Also, we demonstrate relation between avascular necrosis and some risk factors like low hemoglobin and hematocrit levels, frequent blood transfusion, use of hydroxyurea and long-term use of high dose steroid.

Copy Right, IJAR, 2017,. All rights reserved.

\section{Introduction:-}

Sickle cell disease (SCD) is the commonest genetic blood disorder [1]. Every year, around 330,000 babies are born with inherited hemoglobin disorder, 83\% of them have SCD [2]. According to WHO, between 20 to 25 million people worldwide have SCD, 12 to 15 million in Africa, 5 to 10 million in India and about 3 million distributed worldwide [3]. SCD has wide distribution in the Middle Eastern Arab countries [4]. In Saudi Arabia the overall 
prevalence of sickle cell carriers ranged from $2 \%$ to $27 \%$, but up to $1.4 \%$ had SCD. The prevalence of SCD in Saudi Arabia has a significantly uneven geographical distribution, it is most common in the Eastern region of Saudi Arabia [5]. SCD is a result of mutation in genes responsible for hemoglobin synthesis, leading to production of abnormal defective hemoglobin called (HbS). The RBCs which contain this abnormal hemoglobin, under certain conditions, become irregular and sickled in shape. Representing clinically in form of anemia due to hemolysis and insufficient hemoglobin synthesis, recurrent painful vaso-occlusive episodes, intense multi-organ effects and infarctions [6]. SCD has an impact on all human body systems including central nervous system, cardiovascular, respiratory, gastrointestinal, urinary tract and musculoskeletal systems. The pathophysiology of bone diseases in SCD is not fully understood, but it mostly results from either vaso-occlusion or bone marrow hyperplasia [7]. Sickled RBCs lead to thrombosis followed by infarction and necrosis which affect bone integrity. Chronic Hemolysis of Sickled RBCs leads to bone marrow hyper stimulation followed by expansion, causing bone structure irregularities and bone cortical thinning as well [7]. Clinically, bone involvement in SCD can be either in acute form such as painful crisis and osteomyelitis or chronic form like osteonecrosis, arthritis, osteopenia and osteoporosis [1]. Osteonecrosis or avascular necrosis (AVN) is a serious complication threatening the quality of SCD patients' lives [8]. It occurs due to complete loss of supply to bones articular surfaces [8]. It has been reported that even patients with mild forms of SCD present with AVN frequently [9]. Patients with AVN can be either symptomatic complaining of hip pain, pain with movement and restriction of joints range of movement or can be asymptomatic especially in early stages [10]. Although it is the commonest clinical presentation of SCD, it has not been investigated sufficiently $[7,11]$. One study on patients with unilateral hip pain reported radiological changes suggesting AVN of the contralateral asymptomatic hip in 39\% of patients [12]. Osteonecrosis typically affect the hip joint, but it can affect several joints including spine, knees and feet as well [10]. Bilateral disease is common and may occur in 56\% of patients [13]. The prevalence of AVN has been investigated in some studies previously. In a 5 years prospective study in USA, 2590 patients with sickle cell disease were investigated to assess the prevalence, it showed that $9.8 \%$ of them had osteonecrosis. Moreover, it has been noted that patients with $\mathrm{Hb}$ SS and $\alpha$-thalassemia trait have more risk of developing AVN [14]. The same study group has been used to assess the prevalence of osteonecrosis in humeral head, 5.6\% of patients had radiological changes [15]. A more recent study was done in New York at Montefiore Medical Center in 2011 showed an increase of the previous reported prevalence to $12.4 \%$ of all sickle cell genotypes13. In 2007, a 15 years retrospective study was done in Nigeria, it showed that $15.9 \%$ of patients with SCD have clinical and radiological evidence of AVN [16]. Another similar study was done on adult Kuwaitis with SCD reported that $48.6 \%$ of them had AVN, $64.7 \%$ of those affected had a history of frequent vaso-occlusive crisis [17]. Several risk factors for developing AVN in SCD were identified in previous studies. Clinical parameters like recurrent vaso-occlusive crisis and high rate of hospitalizations per year indicate higher risk of AVN [18]. Another study was done at the University Hospital of the West Indies investigated the hematological indices of 50 patients who reported to have AVN, it showed an association between high total hemoglobin and low fetal hemoglobin levels with development of AVN [18]. High hematocrit, hydroxyurea treatment, reduced WBCs, high creatinine levels, male gender, coexistent alpha thalassemia trait and vitamin D deficiency also reported to be positively associated with AVN [8,13]. Vitamin D and calcium levels are critical factors for maintaining an optimum healthy bone structure [7]. Due to multiple factors, patients with SCD reported to have higher prevalence of Vitamin D deficiency than normal population, defining deficiency as vitamin D below $20 \mathrm{ng} / \mathrm{ml}$, it ranged from $56.4 \%$ to $96.4 \%$ [19]. Moreover, they found that patients with bone involvement like AVN and vertebral compression fractures had associated vitamin D deficiency [19]. Therefore, a randomized double-blind pilot study was conducted recently to determine high-dose vitamin D efficacy in treating chronic pain in patients with SCD [18]. Although some patients remained asymptomatic, many experienced pain and undergo hip arthroplasty. The identification of risk factors before the onset of osteonecrosis may help the physician for early institution of preventive and therapeutic protocols. Due to lack of researches about AVN in SCA in our region, there is a persistent need to assess the prevalence of avascular necrosis among adult patients with sickle cell disease in King Fahad Hospital, the risk factors associated with avascular necrosis and to evaluate the relation between Calcium and vitamin D deficiency with AVN.

\section{Objectives:-}

1- To study the prevalence of avascular necrosis in adult patients with sickle cell disease at King Fahad Hospital.

2- To assess the prevalence of avascular necrosis among sickle cell disease patients.

3- To assess the risk factors associated with avascular necrosis.

4- To evaluate the relation between Calcium and vitamin D deficiency with avascular necrosis. 


\section{Methodology:-}

\section{Study design:-}

This is a retrospective study of sickle cell disease patients mainly from Madinah region in Saudi Arabia from 2010 to 2017. The aim of the study is to assess the prevalence of avascular necrosis in adult patients with sickle cell disease at King Fahad Hospital. All recruited subjects of this study were actively involved in attending hematology and orthopedic clinics or admission to medical and orthopedic wards. Data at steady state will be extracted from the hospital computed database and patient medical records. Patients who were not homozygous S (HbSS) on hemoglobin electrophoresis and those who had developed AVN at presentation (to avoid a possible confounding effect of AVN-associated increase in these parameters) and patients below 18 years will be excluded from the study. For each patient, the following will be recorded: age, sex, presence of AVN, bilateral involvement, clinical presentation, hematology and biochemistry lab values (total hemoglobin, hematocrit, RBCS, WBCs, MCV, platelet, bilirubin, calcium, ferritin and Vit D levels), MRI findings, blood transfusions and hip replacement. These data will be entered in data sheet electronically and manually. Analysis will be done using SPSS version (21.0), parametric and non-parametric tests will be used. Approval will be obtained from the Ethical Committee of King Fahad Hospital in Madinah, Saudi Arabia. All ethical consideration and confidentiality will be assured.

\section{Statistical analysis:-}

The collected data will be analyzed using statistical analysis system (SAS). The data will be presented as numerical or categorical. Two types of statistics will be done:

\section{Descriptive statistics:-}

Quantitative data will be demonstrated in tables as means and standard deviation, where appropriate.

\section{Analytical statistics:-}

The Chi-square test will be used for qualitative variables. Also, differences between mean values will be tested for statistical significance using $\mathrm{T}$ - test. The level of significance will be established as $\mathrm{P}<0.05$.

\section{Results:-}

Population \& Sample of the Study:-

The study population includes all patients with sickle cell anemia in King Fahad Hospital in Madinah. A sample of (220) patients was selected randomly, the next table shows their properties according to their personal data.

Table 1:- Distribution of the patients to the demographic data.

\begin{tabular}{|c|c|c|c|c|}
\hline \multicolumn{2}{|c|}{ Variable } & $\mathrm{N}$ & $\%$ & P-value \\
\hline \multirow[t]{2}{*}{ Gender } & Male & 128 & 58.2 & \multirow{2}{*}{$0.015^{*}$} \\
\hline & Female & 92 & 41.8 & \\
\hline \multirow[t]{5}{*}{ Age (years) } & Less than 18 & 17 & 7.7 & \multirow[t]{5}{*}{$0.000 *$} \\
\hline & $18-25$ & 88 & 40.0 & \\
\hline & $26-40$ & 93 & 42.3 & \\
\hline & $41-60$ & 20 & 9.1 & \\
\hline & More than 60 & 2 & .9 & \\
\hline \multirow[t]{2}{*}{ Nationality } & Saudi & 190 & 86.4 & \multirow[t]{2}{*}{$0.000 *$} \\
\hline & Non Saudi & 30 & 13.6 & \\
\hline \multirow[t]{2}{*}{ Residency } & Madina & 206 & 93.6 & \multirow[t]{2}{*}{$0.000 *$} \\
\hline & Outside Madina & 14 & 6.4 & \\
\hline
\end{tabular}

Chi-squared test: *Significant at 0.05

It is clear from the previous table that almost $58 \%$ of the patients were males, while almost $42 \%$ of them were females. And their distribution according to their ages almost $42 \%$ of them were between (26-40) years old, almost $40 \%$ of them were between (18-25) years old, almost 9\% of them were between (41-60) years old, almost $8 \%$ of them were less than (18) years old, and almost $1 \%$ of them were more than (60) years old. And their distribution according to nationality, almost $86 \%$ of them were Saudi, while almost $14 \%$ of them were Non-Saudis. And their distribution according to Residency, almost $94 \%$ of them were lived in Madina, while almost $6 \%$ of them were lived outside Madina. The next figure concludes all the previous results. 


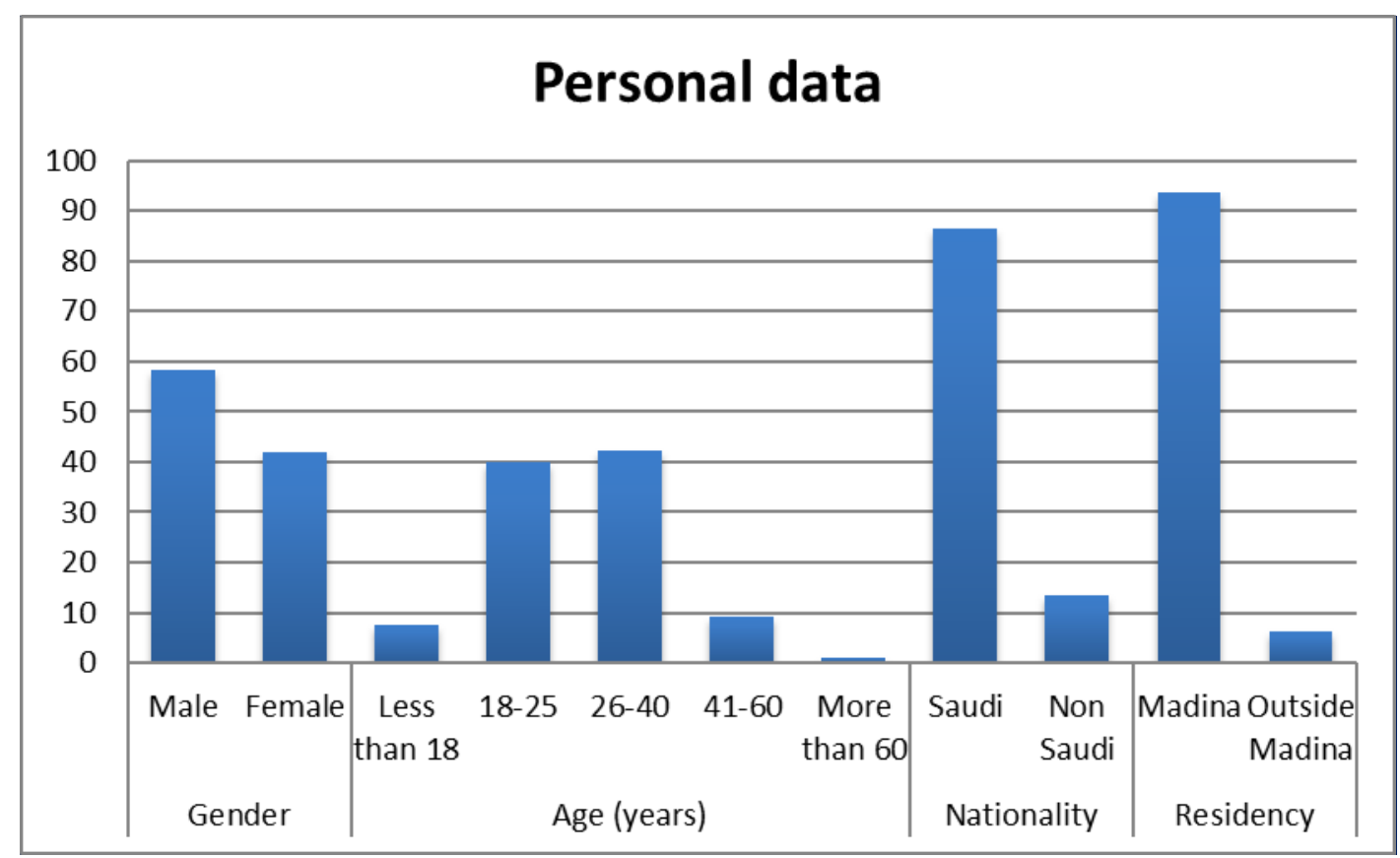

\section{Statistical methods:-}

Figure (1):- Distribution of the patients to the demographic data.

The statistical analysis program (SPSS v.22) was been used in the study in data entry and analysis, with the use of necessary statistical methods to achieve the objectives of the study. The following statistical methods were used include frequencies, percentages, graphs and chi-square test.

\section{Results:-}

The following table shows the distribution of patients with sickle cell anemia in terms of other diseases (diabetes, pancreatitis, AIDS, systemic lupus erythematosus, family history of sickle cell anemia, where we note that $4 \%$ of sickle cell anemia patients suffer from diabetes, $2 \%$ suffer from pancreatitis, $1 \%$ have AIDS, and $1 \%$ have systemic lupus erythematosus. also, we note from the table that $98 \%$ of patients with sickle cell anemia have relatives who have the same disease.

Table (2):- shows the distribution of patients with sickle cell anemia in terms of other diseases (diabetes, pancreatitis, AIDS, systemic lupus erythematosus, family history of sickle cell anemia.

\begin{tabular}{|l|l|l|l|}
\hline & $\begin{array}{l}\text { Yes } \\
\mathrm{N}(\%)\end{array}$ & $\begin{array}{l}\text { No } \\
\mathrm{N}(\%)\end{array}$ & P-value \\
\hline Diabetic & $8(3.6)$ & $212(96.4)$ & $0.000^{*}$ \\
\hline Pancreatitis & $4(1.8)$ & $216(98.2)$ & $0.000^{*}$ \\
\hline HIV/AIDS & $1(.5)$ & $219(99.5)$ & $0.000^{*}$ \\
\hline Systemic lupus erythematosus & $1(.5)$ & $219(99.5)$ & $0.000^{*}$ \\
\hline Family History of SCA & $215(97.7)$ & $5(2.3)$ & $0.000^{*}$ \\
\hline
\end{tabular}

Chi-squared test: *Significant at 0.05

The following table shows the distribution of sickle cell anemia patients in terms analysis (hemoglobin, hematocrit, RBCs, WBC count, Platelet, MCV, Reticulocyte count, Ca level, vitamin D). Where we note that $70 \%$ of SCA patients have a hemoglobin level of $(7.0 \mathrm{~g} / \mathrm{dl}-10.4 \mathrm{~g} / \mathrm{dl})$ and $18.2 \%$ have hemoglobin levels $(10.5 \mathrm{~g} / \mathrm{dl}-15.5 \mathrm{~g} /$ dl) and $11.8 \%$ have hemoglobin levels less than $(7.0 \mathrm{~g} / \mathrm{dl})$. And for the analysis of hematocrit; we note that the vast majority of SCA patients $(97.7 \%$ ) of them have hematocrit less than $40 \%$, while $2.3 \%$ of them ranges from the level of hematocrit between (40\%-54\%). As for the number of red blood cells, $48.6 \%$ of SCA patients have less than (3.0 $\left.* 10^{\wedge} 12 / \mathrm{L}\right)$ and $49.5 \%$ of SCA patients have RBCs between $\left(3.0-5.30 * 10^{\wedge} 12 / \mathrm{L}\right)$, while $1.8 \%$ of SCA patients have RBCs more than $\left(5.30 * 10^{\wedge} 12 / \mathrm{L}\right)$. As for the number of white blood cells, 55.5\% of SCA patients have WBC between $\left(4-12 * 10^{\wedge} 9 / \mathrm{L}\right), 41.8 \%$ of SCA patients have WBC more than $\left(12 * 10^{\wedge} 9 / \mathrm{L}\right)$, while $2.7 \%$ of SCA patients have WBC less than $\left(4 * 10^{\wedge} 9 / \mathrm{L}\right)$. For platelet analysis, 50.9\% of SCA patients have platelet 
between $\left(150-400 * 10^{\wedge} 9 / \mathrm{L}\right), 38.6 \%$ of SCA patients have platelet $(400 \times 10 \wedge 9 / \mathrm{L})$, While $10.5 \%$ of SCA patients have a platelet less than $(150 * 10 \wedge 9 / \mathrm{L})$. For MCV analysis we find that it's less than (80) for 35.9\% of SCA patients, ranging from (80-100) for 53.6\% of SCA patients, and more than (100) for $10.5 \%$ of SCA patients. For the reticulocyte count, we note that it's more than $\left(100 * 10^{\wedge} 9 / \mathrm{L}\right)$ for $61.9 \%$ of SCA patients, and less than $(50$ $\left.* 10^{\wedge} 9 / \mathrm{L}\right)$ for $23.8 \%$ of SCA patients, and between $\left(50-100 * 10^{\wedge} 9 / \mathrm{L}\right)$ for $14.3 \%$ of SCA patients. Calcium levels ranged between $(8.0$ - 10.4) for $86.1 \%$ of SCA patients, less than $(8.0 \%)$ for $13.4 \%$ of SCA patients, and more than $(10.4 \%)$ for $0.5 \%$ of SCA patients. Finally, for the level of vitamin D, we find it less than (10 NG / ML) for $49.2 \%$ of SCA patients, ranging from (10 - $24 \mathrm{NG} / \mathrm{ML})$ for $36.1 \%$ of SCA patients, and ranging from (25 - $80 \mathrm{NG} \mathrm{/}$ $\mathrm{ML})$ for $14.8 \%$ of SCA patients.

Table (3):-shows the distribution of sickle cell anemia patients in terms analysis (hemoglobin, hematocrit, RBCs, WBC count, Platelet, MCV, Reticulocyte count, Ca level, vitamin D).

\begin{tabular}{|c|c|c|c|c|}
\hline & & $\mathrm{N}$ & $\%$ & P-value \\
\hline \multirow[t]{3}{*}{ Hemoglobin level } & Less than $7.0 \mathrm{~g} / \mathrm{dl}$ & 26 & 11.8 & \multirow[t]{3}{*}{$0.000 *$} \\
\hline & $7.0 \mathrm{~g} / \mathrm{dl}-10.4 \mathrm{~g} / \mathrm{dl}$ & 154 & 70.0 & \\
\hline & $10.5 \mathrm{~g} / \mathrm{dl}-15.5 \mathrm{~g} / \mathrm{dl}$ & 40 & 18.2 & \\
\hline \multirow[t]{2}{*}{ Hematocrit } & Less than $40 \%$ & 215 & 97.7 & \multirow[t]{2}{*}{$0.000 *$} \\
\hline & $40 \%-54 \%$ & 5 & 2.3 & \\
\hline \multirow[t]{3}{*}{ RBCs } & Less than $3.0 * 10^{\wedge} 12 / \mathrm{L}$ & 107 & 48.6 & \multirow[t]{3}{*}{$0.000^{*}$} \\
\hline & $3.0-5.30 * 10^{\wedge} 12 / \mathrm{L}$ & 109 & 49.5 & \\
\hline & More than $5.30 * 10^{\wedge} 12 / \mathrm{L}$ & 4 & 1.8 & \\
\hline \multirow[t]{3}{*}{ WBC count } & Less than $4 * 10^{\wedge} 9 / \mathrm{L}$ & 6 & 2.7 & \multirow[t]{3}{*}{$0.000 *$} \\
\hline & $4-12 * 10^{\wedge} 9 / \mathrm{L}$ & 122 & 55.5 & \\
\hline & More than $12 * 10^{\wedge} 9 / \mathrm{L}$ & 92 & 41.8 & \\
\hline \multirow[t]{3}{*}{ Platelet } & Less than $150 * 10^{\wedge} 9 / \mathrm{L}$ & 23 & 10.5 & \multirow[t]{3}{*}{$0.000^{*}$} \\
\hline & $150-400 * 10^{\wedge} 9 / \mathrm{L}$ & 112 & 50.9 & \\
\hline & More than $400 * 10^{\wedge} 9 / \mathrm{L}$ & 85 & 38.6 & \\
\hline \multirow[t]{3}{*}{$\mathrm{MCV}$} & Less 80 & 79 & 35.9 & \multirow[t]{3}{*}{$0.000 *$} \\
\hline & $80-100$ & 118 & 53.6 & \\
\hline & More than 100 & 23 & 10.5 & \\
\hline \multirow[t]{4}{*}{ Reticulocyte count } & Less than $50 * 10^{\wedge} 9 / \mathrm{L}$ & 10 & 23.8 & \multirow[t]{4}{*}{$0.000^{*}$} \\
\hline & $50-100 * 10^{\wedge} 9 / \mathrm{L}$ & 6 & 14.3 & \\
\hline & More than $100 * 10^{\wedge} 9 / \mathrm{L}$ & 26 & 61.9 & \\
\hline & System & 178 & & \\
\hline \multirow[t]{4}{*}{ Ca level } & Less than 8.0 & 29 & 13.4 & \multirow[t]{4}{*}{$0.000^{*}$} \\
\hline & $8.0-10.4$ & 186 & 86.1 & \\
\hline & More than 10.4 & 1 & .5 & \\
\hline & System & 4 & & \\
\hline \multirow[t]{4}{*}{ Vit D } & Less than $10 \mathrm{NG} / \mathrm{ML}$ & 30 & 49.2 & \multirow[t]{4}{*}{$0.004 *$} \\
\hline & $10-24 \mathrm{NG} / \mathrm{ML}$ & 22 & 36.1 & \\
\hline & $25-80 \mathrm{NG} / \mathrm{ML}$ & 9 & 14.8 & \\
\hline & System & 159 & & \\
\hline
\end{tabular}

Chi-squared test: *Significant at 0.05

The following table shows the distribution of sickle cell anemia patients in terms of (Presence of Avascular Necrosis, Hydroxyurea, Folic Acid, Blood transfusion, Exchange transfusion, Ventilator, Steroids, and Bisphosphonate). Where we note that $7.3 \%$ of SCA patients have avascular necrosis, $63.8 \%$ have blood transfusion, $3.7 \%$ take Ventilator, and $34.9 \%$ take Steroids.

Table (4):- shows the distribution of sickle cell anemia patients in terms of (Presence of Avascular Necrosis, Hydroxyurea, Folic Acid, Blood transfusion, Exchange transfusion, Ventilator, Steroids, and Bisphosphonate).

\begin{tabular}{|c|c|c|c|c|}
\hline & $\begin{array}{l}\text { Yes } \\
\mathrm{N}(\%)\end{array}$ & $\begin{array}{l}\text { No } \\
\mathrm{N}(\%)\end{array}$ & Missing & P-value \\
\hline Presence of avascular necrosis & $16(7.3)$ & $204(92.7)$ & & $0.000 *$ \\
\hline
\end{tabular}




\begin{tabular}{|l|l|l|l|l|}
\hline Hydroxyurea & $125(57.9)$ & $91(42.1)$ & 4 & $0.021^{*}$ \\
\hline Folic acid & $190(87.6)$ & $27(12.4)$ & 3 & $0.000^{*}$ \\
\hline Blood transfusion & $139(63.8)$ & $79(36.2)$ & 2 & $0.000^{*}$ \\
\hline Exchange transfusion & $36(16.7)$ & $179(83.3)$ & 5 & $0.000^{*}$ \\
\hline Ventilator & $8(3.7)$ & $208(96.3)$ & 4 & $0.000^{*}$ \\
\hline Steroids & $76(34.9)$ & $142(65.1)$ & 2 & $0.000^{*}$ \\
\hline Bisphosphonate & $0(0.0)$ & $216(100.0)$ & 4 & $0.000^{*}$ \\
\hline
\end{tabular}

Chi-squared test: *Significant at 0.05

The following table shows the relationship between Presence of avascular necrosis, and each of (Diabetic, Pancreatitis, HIV / AIDS, Systemic lupus erythematosus, Family History of SCA, Ca level, Vit D). Where we note that there is a relationship between Presence of Avascular Necrosis and Diabetes, and there is a relationship between Presence of Avascular Necrosis and systemic lupus erythematosus, while there was no relationship between the Presence of avascular necrosis and all of (Pancreatitis, HIV / AIDS, Family History of SCA, Ca level, Vit D)

Table (5):- shows the relationship between Presence of avascular necrosis, and each of (Diabetic, Pancreatitis, HIV / AIDS, Systemic lupus erythematosus, Family History of SCA, Ca level, Vit D).

\begin{tabular}{|c|c|c|c|c|}
\hline & & \multicolumn{2}{|c|}{$\begin{array}{l}\text { Presence of avascular } \\
\text { necrosis }\end{array}$} & \multirow[t]{2}{*}{ P-value } \\
\hline & & Yes & No & \\
\hline \multirow[t]{2}{*}{ Diabetic } & Yes & 2 & 6 & \multirow[t]{2}{*}{.049} \\
\hline & No & 14 & 198 & \\
\hline \multirow[t]{2}{*}{ Pancreatitis } & Yes & 0 & 4 & \multirow[t]{2}{*}{.572} \\
\hline & No & 16 & 200 & \\
\hline \multirow[t]{2}{*}{ HIV/AIDS } & Yes & 0 & 1 & \multirow[t]{2}{*}{.779} \\
\hline & No & 16 & 203 & \\
\hline \multirow[t]{2}{*}{ Systemic lupus erythematosus } & Yes & 1 & 0 & \multirow[t]{2}{*}{.000} \\
\hline & No & 15 & 204 & \\
\hline \multirow[t]{2}{*}{ Family History of SCA } & Yes & 16 & 199 & \multirow[t]{2}{*}{.526} \\
\hline & No & 0 & 5 & \\
\hline \multirow[t]{3}{*}{ Ca level } & Less than 8.0 & 1 & 28 & \multirow[t]{3}{*}{.651} \\
\hline & $8.0-10.4$ & 15 & 171 & \\
\hline & More than 10.4 & 0 & 1 & \\
\hline \multirow[t]{3}{*}{ Vit D } & Less than $10 \mathrm{NG} / \mathrm{ML}$ & 2 & 28 & \multirow[t]{3}{*}{.700} \\
\hline & $10-24$ NG/ML & 3 & 19 & \\
\hline & $25-80 \mathrm{NG} / \mathrm{ML}$ & 1 & 8 & \\
\hline
\end{tabular}

Chi-squared test: *Significant at 0.05

\section{Discussion:-}

According to the results of this study, most patients were males, aged between 26 and 40 years. These findings are similar to previous report on SCA from the study area [20]. AVN is considered the leading cause of disability among sickle cell anemia patients [8]. However, this study set out with the aim of assessing the prevalence of AVN in adult patients with SCA at King Fahad Hospital. Of 220 SCA patients attended at King Fahad Hospital in a period of 7 years, $16(7.3 \%)$ had AVN. Lower than the prevalence reported by Milner in $1991(9.8 \%)$, and it is far below the more recent studies like the study was done in the USA by Darleen R. Powars which found that (15\%) of subjects have AVN, the study in Kuwait by R. Marouf reported an increase in the prevalence to (48.6\%), and in London by H. E. Ware the prevalence reached $(41 \%)[15,21,17,22]$. The recent studies claim that this increase in prevalence is due to advancement of diagnosis and radiological imaging. However, in general the prevalence of AVN is underestimated as there is no screening program applied for silent AVN patients, who were reported to reach (47.3\%) of all cases of AVN [15]. Although AVN is a well-known complication of SCA, the risk factors to develop AVN in SCA is still vague [23]. We studied the hematological indices of all subjects, we found that the majority of SCA patients have a lower hemoglobin and hematocrit levels $(7.0-10.4 \mathrm{~g} / \mathrm{dl}$ and less than $40 \%$, respectively). These results support previous studies conducted in Nigeria and Brazil [23,24,25]. Although maintaining hemoglobin levels in SCA patients is a principle in managing SCA, it has been reported that patients 
who tend to develop complications like frequent sever crisis and AVN have higher hemoglobin, hematocrit and RBCs levels than others [23]. Another important finding was that 57.9\% of patients take hydroxyurea. According to some researches, patients who were exposed to hydroxyurea had higher risk of developing AVN. However, the effect of hydroxyurea in rising hemoglobin and hematocrit levels leading to increase viscosity and sickling of cells in head of femur circulation. Relying on the previous theory and the increase of AVN incidence in the exposed group they considered hydroxyurea as a confirmed risk factor for developing AVN [13,17]. In further studies it will be useful for practitioners to determine the required and safe hemoglobin levels to be maintained for SCA patients. In this study most of SCA patients have average WBCs, platelets and MCV levels. Further studies to evaluate the hematological indices in SCA patients who developed AVN are needed to take the appropriate prophylactic measures for patients susceptible to develop AVN. The result of this study also shows that $86.1 \%$ of SCA patients have normal serum calcium levels ranged between $(8.0$ - 10.4). While $13.4 \%$ of SCA patients have low serum calcium levels. These results match those observed in earlier studies on SCA patients in KSA and USA [26,27]. A possible explanation for this might be that SCA patients have hypocalcemia tendency due to multiple factors like poor intestinal absorption of calcium and vitamin D, which stimulate PTH secretion that might contribute to the skeletal changes seen in SCA patients [26]. Another important finding was that almost half of SCA patients have vitamin D deficiency. These results are in line with those of previous studies on prevalence of vitamin D deficiency among SCA patients which was mentioned in the literature review [19]. Anyhow, previous reports on vitamin D levels in normal population of KSA, indicated that the majority of Saudis have low vitamin D levels mostly due to low dietary intake and sunlight avoidance [26]. In this study we did not detect any relationship between presence of AVN with vitamin D and calcium levels. A further study with more focus on the rule of calcium and vitamin D supplementation in preventing AVN is therefore suggested. We noted that $63.8 \%$ of SCA patients have blood transfusion. In a cross-sectional study was done in brazil of two groups, the group who has AVN reported a higher blood transfusion rate than the other group without AVN [28]. However, blood transfusion rate mostly indicates severity of the disease in general but not the risk of developing AVN in particular. Another important finding was that $34.9 \%$ of SCA patients take Steroids. The long-term use of high dose steroid is reported to be an iatrogenic condition associated with AVN [29]. Although the pathogenesis of glucocorticoid induced AVN is not totally understood, many hypotheses were studied in animal models include fat cell hypertrophy, fat embolism, intravascular coagulation and osteocyte apoptosis [30]. Glucocorticoid induced AVN prevalence reach 10\% in USA [29]. Most of these cases associated with post kidney transplantation and SLE [29]. Moreover, in this study we noted a relationship between SLE and presence of AVN, this relationship may partly be explained by the long-term use of steroids by SLE patients. Further studies to determine the relation between the dose, route of administration and duration of steroid intake with developing AVN will be useful, beside establishing an AVN screening program for long-term glucocorticoid users. We note that $4 \%$ of SCA patients suffer from diabetes, $2 \%$ suffer from pancreatitis, $1 \%$ have AIDS, and $1 \%$ have SLE. A relationship between presence of AVN and DM was detected in this study. In previous researches the relationship between diabetes and developing pedal and jaw osteonecrosis is already established [31]. In earlier study that investigated association of DM and jaw osteonecrosis, the prevalence of microvascular diseases like neuropathy, retinopathy and nephropathy was significantly higher in diabetics who had jaw necrosis than in the control group [32]. Very little was found in the literature on the question of association between diabetes and AVN of hips. The pathogenesis of AVN in DM is not completely clear, but it may be attributed to complex interactions between diabetic vasculopathy, neuropathy, structural deformity and disruptive immune system [31]. Further work is required to establish the viability of this relationship.

\section{Limitations:-}

This study has several limitations. First, it was conducted at one major hospital in Al- Madinah and that exclude many other rural and urban centers which makes these findings less generalizable. Medical records were deficient, and some data have not been mentioned in patients' files like family history of the patient. Moreover, some lab investigations were not completely done to all patient. Many patients have not had MRI reports while some reports did not include stage of AVN and other details regarding condition of the patients. Regarding treatment of AVN, files were lack of follow up and progression notes of the patient after medical or surgical management. Therefore, it was not possible to demonstrate the effectiveness of different types of treatment on patient's life style. Additionally, the patients' medical records could not be linked to records from other healthcare facilities, such as primary health care centers and other hospitals around the country. It is unfortunate that the study did not establish the exact dose and duration of steroid and hydroxyurea use to develop AVN. Finally, in the literature review we faced many difficulties in finding data regarding AVN of SCA patients in middle east and Saudi Arabia in particular. 


\section{Conclusion:-}

In conclusion, this study aimed to assess the prevalence of AVN in adult patients with SCA at King Fahad Hospital. Of 220 SCA patients attended at King Fahad Hospital in a period of 7 years, 16 (7.3\%) had AVN. Also, we demonstrate relation between AVN and some risk factors like low hemoglobin and hematocrit levels, frequent blood transfusion, use of hydroxyurea and long-term use of high dose steroid. We didn't detect any relation between AVN and low calcium and vitamin D deficiency.

\section{Recommendation:-}

Based on the findings of the present study, the following recommendations are suggested:

1. Investigations should be done completely for all sickle cell patients and included in their files.

2. MRI should be done to all patients with Avascular necrosis.

3. MRI reports would be more advantageous if they contain the stage of Avascular necrosis.

4. Orthopedic decisions and management must be included in the patient's file.

5. Medical files should contain patient's OPD follow up note after medical treatment or surgery.

6. To increase the sample and conduct the study at other hospitals of Madina.

7. Further research is recommended on other chronic diseases such as (epilepsy) and its relationship with SCD.

\section{Acknowledgement:-}

At the outset, we would like to express our deep and sincere gratitude to the following people without whose support this research project would not have been a success. We would like to sincerely thank all the data collectors who helped us in our project, namely:

\section{Abdulaziz Mohammed Hammudah}

\section{Ahmed Hamza Mohammed Alhadi}

Yara Ahmed Elmaghraby

MashaelAbdulhadi AL-loqmani

We also owe our gratitude to authority of King Fahad Hospital in Madina for facilitating our study by providing a suitable environment and encouraging us from the be-ginning up to this far. We are indebted and grateful to every patient who participated in this study. Finally, we are extending our thanks to everyone who has supported us to complete the research work directly or indirectly.

\section{References:-}

1. Bezerra G, Silva Junior D, De E, Daher F, Airton F, Da Rocha C. Osteoarticular involvement in sickle cell disease. Rev Bras HematolHemoter. 2012;34(2):156-164. doi:10.5581/1516-8484.20120036.

2. Modell B, Darlison M. Global epidemiology of haemoglobin disorders and derived service indicators. Bull World Health Organ. 2008;86(6):480-487. doi:10.2471/BLT.06.036673.

3. Saraf SL, Molokie RE, Nouraie M, et al. Differences in the clinical and genotypic presentation of sickle cell disease around the world. PaediatrRespir Rev. 2017;15(1):4-12. doi:10.1016/j.prrv.2013.11.003.

4. El-Hazmi MA, Al-Hazmi AM, Warsy AS. Sickle cell disease in Middle East Arab countries. Indian J Med Res. 2011;134(November):597-610. doi:10.4103/0971-5916.90984.

5. Jastaniah W. Epidemiology of sickle cell disease in Saudi Arabia. Ann Saudi Med. 2011;31(3):289-293. doi:10.4103/0256-4947.81540.

6. Chung SM, Ralston EL. Necrosis of the femoral head associated with sickle-cell anemia and its genetic variants. A review of the literature and study of thirteen cases. J Bone Joint Surg Am. 1969;51(1):33-58.

7. Osunkwo I. An update on the recent literature on sickle cell bone disease. CurrOpinEndocrinol Diabetes Obes. 2013;20(6):539-546. doi:10.1097/01.med.0000436192.25846.0b.

8. Ballas SK, Kesen MR, Goldberg MF, et al. Beyond the Definitions of the Phenotypic Complications of Sickle Cell Disease: An Update on Management. Sci World J. 2012;2012:1-55. doi:10.1100/2012/949535.

9. Adekile AD, Gupta R, Yacoub F, Sinan T, Al-Bloushi M, Haider MZ. Avascular necrosis of the hip in children with sickle cell disease and high $\mathrm{Hb} \mathrm{F}$ : magnetic resonance imaging findings and influence of alpha-thalassemia trait. ActaHaematol. 2001;105(1):27-31. doi:46529.

10. Mont MA, Zywiel MG, Marker DR, McGrath MS, Delanois RE. The natural history of untreated asymptomatic osteonecrosis of the femoral head: a systematic literature review. J Bone Joint Surg Am. 2010;92(12):21652170. doi:10.2106/JBJS.I.00575.

11. Almeida A, Roberts I. Bone involvement in sickle cell disease. $\mathrm{Br}$ J Haematol. 2005;129(4):482-490. doi:10.1111/j.1365-2141.2005.05476.x. 
12. Hernigou P, Bachir D, Galacteros F. The natural history of symptomatic osteonecrosis in adults with sickle-cell disease. J Bone Joint Surg Am. 2003;85-A(3):500-504.

13. Mahadeo K.M., Oyeku S., Taragin B. et A. Increased prevalence of osteonecrosis of the femoral head in children and adolescents with sickle-cell disease. Am J Hematol. 2011;86(9):806-808.

14. Milner PF, Kraus AP, Sebes JI, et al. Osteonecrosis of the humeral head in sickle cell disease. ClinOrthopRelat Res. 1993;(289):136-143.

15. Milner PF, Kraus AP, Sebes JI, et al. Sickle cell disease as a cause of osteonecrosis of the femoral head. N Engl J Med. 1991;325(21):1476-1481. doi:10.1056/NEJM199111213252104.

16. Akinyoola AL, Adediran IA, Asaleye CM. Avascular necrosis of the femoral head in sickle cell disease in Nigeria: a retrospective study. Niger Postgrad Med J. 2007;14(3):217-220.

17. Marouf R, Gupta R, Haider MZ, Al-Wazzan H, Adekile AD. Avascular necrosis of the femoral head in adult Kuwaiti sickle cell disease patients. ActaHaematol. 2003;110(1):11-15. doi:10.1159/000072406.

18. Osunkwo I, Ziegler TR, Alvarez J, et al. High dose vitamin D therapy for chronic pain in children and adolescents with sickle cell disease: Results of a randomized double blind pilot study. Br J Haematol. 2012;159(2):211-215. doi:10.1111/bjh.12019.

19. Nolan VG, Nottage KA, Cole EW, Hankins JS, Gurney JG. Prevalence of Vitamin D deficiency in sickle cell disease: A systematic review. PLoS One. 2015;10(3):1-12. doi:10.1371/journal.pone.0119908.

20. Al-qurashi MM, El-mouzan MI, Al-herbish AS, Al-salloum AA, Al-omar AA. adolescents. 2008;966(C):14801483.

21. Powars DR, Hiti A, Ramicone E, Johnson C, Chan L. Outcome in Hemoglobin SC Disease: A Four-Decade Observational Study of Clinical , Hematologic , and Genetic Factors. 2002;215(May 2001):206-215. doi:10.1002/ajh.10140.

22. Ware HE, Brooks AP, Toye R, Berney SI. SICKLE SILENT DISEASE NECROSIS AND OF THE of. 1991;73(6):947-949.

23. Hawker H, Unit TE. Haematological factors associated with avascular necrosis of the femoral head in homozygous sickle cell disease. 1982:29-34.

24. Ugwu AO, Ibegbulam OG, Nwagha TU, Madu AJ, Ocheni S, Okpala I. Clinical and Laboratory Predictors of Frequency of Painful Crises among Sickle Cell Anaemia Patients in Nigeria. 2017;11(6):10-13. doi:10.7860/JCDR/2017/26446.10042.

25. Journal B, Gabriel P, Ana S, et al. RevistaBrasileira de Hematologia e Hemoterapia Original article Clinical and laboratory profile of patients with sickle cell anemia. Rev Bras HematolHemoter. 2016;39(1):40-45. doi:10.1016/j.bjhh.2016.09.007.

26. Mohammed S, Addael S, Suleiman S, Adzakul F, Richards J. Serum calcium, parathyroid hormone , and vitamin D status in children and young adults with sickle cell disease. 1993:45-51.

27. Adewoye AH, Chen TC, Ma Q, et al. Sickle cell bone disease: Response to vitamin D and calcium. 2008;(October 2007):271-274. doi:10.1002/ajh.21085.

28. Avascular necrosis of the femoral head in sickle cell disease in pediatric patients suffering from hip dysfunction. 2016.

29. Chan KL, Mok CC. Glucocorticoid-Induced Management Avascular Bone Necrosis : Diagnosis and. 2012:449457.

30. Wang GJ, Cui Q, Balian G. The Nicolas Andry award. The pathogenesis and prevention of steroid-induced osteonecrosis. ClinOrthopRelat Res. 2000;(370):295-310.

31. Naidoo P, Bs MB, Liu VJ, Bs MB, Sci BM, Mautone M. Lower limb complications of diabetes mellitus : a comprehensive review with clinicopathological insights from a dedicated high-risk diabetic foot multidisciplinary team. 2015;(February). doi:10.1259/bjr.20150135.

32. Molcho S, Peer A, Berg T, Futerman B, Khamaisi M. Diabetes Microvascular Disease and the Risk for bisphosphonate-related Osteonecrosis of the Jaw: A Single Center Study. 2017;98(December):1807-1812. doi:10.1210/jc.2013-2434. 